\title{
New Roles, New Skills: Library and Information Services to Disadvantaged Users
}

\author{
by Dr. Sue Lithgow
}

Public library and infornation services, "are provided on the basis of equality of access for all, regardless of age, race, sex, religion, nationality, language or social status." 1 This basic tenet is dependent upon the qualification that, "specific services and materials must be provided for those who cannot, for whatever reason, use the regular services and materials."2

Those individuals who fall within these parameters are commonly referred to as the 'disadvantaged'. 'Disadvantaged' is therefore considered to be the generic term for such groups as, "linguistic minorities, people with disabilities or people in hospital or prison." 3 These artificial divisions create an immediate dichotomy. As stated in the UNESCO Public Library Manifesto the ultimate aim is to ensure equality of access for all, thereby eliminating the need for the term 'disadvantaged' altogether. However, in seeking to redress the balance of access, disadvantaged users have to be categorised into discrete groups in this way, which effectively intensifies the very barriers that the profession is seeking to break down.

It is therefore important to strike a balance between addressing the needs of specific individuals and incorporating these same needs into mainstream library and information provision. By the same token, segregating users in this way runs the risk of implying the independence and self sufficiency of these groups. To the contrary, the needs of disadvantaged users and the onus for meeting these needs is cross divisional.

This paper considers the professional demands placed upon those providing library and information services to disadvantaged users. The roles and skills that this involves are equally cross divisional. Thus whilst a proportion of these attributes are inevitably user specific, many of them transcend the divide of public, academic and special libraries, sustaining a relevance to the library and information profession as a whole.

With the rapid development of the information superhighway, library and information professionals in both the public and private sector alike, have been forced to reassess their roles and skills accordingly. As Law argues, librarians can manage such change by maintaining their traditional skills. ${ }^{4}$ The organisation of knowledge, quality assurance and user support and instruction will therefore continue to be of central importance to all library and information professionals even in an electronic age. 5

Nowhere is the extent of transferable skills more evident, than in the range of generic skills currently demanded of graduates by prospective employers. In a recent survey by Goulding, the following requirements are listed; enthusiasm flexibility/adaptability/versatility ability to develop/adapt to changes ability to work well in a team and on individual initiative motivation innovation interpersonal skills/customer care skills/communication skills ability to work under pressure 6

However, Goulding goes on to argue that whilst there is at least this degree of common ground between academic, public, government and commercial library needs, clearly there are also a number of skills peculiar to the sector concemed. ${ }^{7}$

Similarly, whilst there are many transferable skills involved in working with the disadvantaged, the nature of the work, the environment and the users will demand a number of job specific qualities. In addition to this, traditional roles and skills will have to be tailored to suit specific needs and in effect will be subject to a range of appropriate weighting factors. Thus, for example, whilst effective communication will continue to be of universal importance, it will take on a new emphasis when working with the deaf or the blind. Likewise, marketing the service to potential users requires added sensitivity in this field, where non-users often have greater barriers to surmount before they can overcome their reluctance to utilise such services.

To illustrate this point further consideration will now be given to the range of skills required by those working in prison libraries. The prison setting provides a useful worked example for a number of reasons. Arguably, prisons present a microcosm of the general population and in this sense all the disadvantaged groups are to a certain extent represented within it. Moreover, the prison context epitomises the need to adapt existing skills to suit the demands of the environment.

Prison librarians are often working as professionals in isolation. However, in addition to the demands facing one person bands, prison librarians also have to contend with working as lone civilians in a closed working environment. As Suvak argues, prison librarians cannot be expected to function effectively unless they fully appreciate the protocol and idiosyncrasies of the prison culture from both the inmate perspective as well as the staff perspective. ${ }^{8}$ 
Mastery of the situation is not enough in itself and "the ability to work in a correctional environment" also requires such attributes as;

the ability to work independently skill in planning and organizing work effectively good communication skills ability to interact with a diverse range of personalities and ethnic groups emotional maturity adaptability sound judgement. 9

These skills represent the prison survival kit, for as Souza points out,

Inmates will test new employees, particularly women, to determine if they will bend the rules, share personal information and opinions, play favourites, be trusting or lack self assurance. ... they will look upon someone who cannot set limits as vulnerable and someone to be manipulated. 10

In view of the nature of the prison environment, adaptability and flexibility are perhaps two of the most important skills the prison librarian can have. The security and care of inmates and staff take precedence over and above all other considerations and subsidiary services such as library provision must therefore adapt accordingly. Prison libraries operate within a highly volatile environment and as already discussed, the unpredictability of the demands placed upon them has the effect of creating a prison weighting factor. ${ }^{11}$ Librarians therefore have to be particularly flexible, for example, to cope with the transient nature of the inmate population or unpredictable library closures as a result of prison officer shortages. Continued exposure to such obstacles also demonstrates the benefits of one final quality, namely "a superb sense of humor," which although invaluable in its own right also provides an "effective means of defusing potentially dangerous situations." 12

So far this paper has concentrated on the range of interpersonal skills required by librarians working with disadvantaged user groups. However the political climate is placing increasing demands upon librarians as managers, particularly as financial managers and information managers. Cuts in public expenditure have placed increasing pressure upon library managers to provide economic, efficient and effective services. Performance measurement and quality assurance have become traditional skills but they are clearly more difficult to implement amongst library and information provision to disadvantaged users, where the impact of services is less tangible. Similarly, in the UK as elsewhere, the government policy of decentralisation has forced library managers to demonstrate their accountability still further. This situation is epitomised by the current Local Govemment Reorganisation (LGR) process in England and Wales. LGR has particularly significant implications for library and information services to disadvantaged users as it is likely to have most impact on "those services that rely most on being networked, shared across a large client base and are relatively expensive to operate." 13 It is therefore likely that the expensive specialist services will decline or disappear altogether as smaller authorities are obliged for reasons of economy to respond to the needs of the majority rather than those of comparatively small groups with special needs. ${ }^{14}$

In the face of potentially diminishing services, practitioners are therefore facing even more pressure to prove the value and subsequent need for such provision. Good leadership skills are not enough in themselves and the profession demands a practical knowledge of "strategic planning, financial planning, budgetary control and marketing." 15 Librarians have therefore been forced to take on the roles of negotiator, arbitrator and bailiff which has in tum increased the need for such skills as intuition, resourcefulness and determination.

The management of change inevitably places increasing importance upon the issue of training. Staff training, end user training and continuing professional development must all be addressed in this respect. In order to ensure effective service provision, librarians in all sectors have to maintain an acute awareness of appropriate developments. In terms of technological advances:

keeping up-to-date with new developments in databases, hosts, CD-ROMS, etc. is already a problem for staff with very little leaming/reading time. The problems of keeping up-to-date with the Internet may be insurmountable. ${ }^{16}$

The problems faced are not ones of volume alone but are those resulting from financial constraints, too.

Providing library and information services to disadvantaged users also demands a range of specific training needs. Librarians in this field will require full training in the use of appropriate specialist equipment, such as that required by blind or deaf users for example. Similarly librarians may need relevant training in terms of the particular group of individuals they are working with and the nature of the environment they are working in. For example, meeting the library and information needs of users with reading difficulties requires specialist training and prison librarians require appropriate induction courses in order to familiarise themselves with security procedures and prison protocol generally.

The availability of suitable training courses is an additional problem and this leads on to the final discussion point of this paper, which is inclusion of library and information services to disadvantaged users as a recognised discipline within library school curricula. If library and information science graduates receive or can elect to receive, at least some initial training in this field, then services stand to benefit accordingly. For many librarians, services to disadvantaged users will be one of many responsibilities as opposed to their specialism and here too a basic grounding or awareness of the main issues concermed will help them to provide a more effective service. By marketing the subject across the profession in this way, graduates can subsequently use this knowledge within whatever library and information sector they may find themselves in, for as discussed earlier, disadvantaged users transcend all subject field divisions. 
Research is currently being conducted in this area by Anne Galler, who has distributed an appropriate survey to library schools across the world. 17 The objectives of the research are as follows;

1. To raise awareness in library school personnel to the special needs of the disadvantaged.

2. To enable library school students to identify these special groups and to respond to their special needs.

3. To compile the results, and prepare guidelines for an inclusive curriculum suggesting the best ways to respond to the needs of the disadvantaged.

4. To stimulate the preparation of special materials. ${ }^{18}$

If the profile and awareness of library and information services to the disadvantaged are to be raised then it is best done at source, where librarians and information professionals of the future can be equipped with the necessary skills to charter the management of change. A heightened awareness will in turn strengthen the mainstay of library and information services to disadvantaged users, namely co-operation. Co-operation is required on all fronts locally, nationally and internationally and not just between fellow library and information services but between voluntary and commercial organisations as well. The needs of disadvantaged users in this respect are very complex and cannot be fully satisfied by any one body. The forging of working partnerships is therefore crucial. In this way, perhaps disadvantaged users can begin to merge into all fields of the library and information profession as users of equal advantage.

\section{References}

1. UNESCO, Public library manifesto (The Hague: IFLA, 1995).

2. Ibid.

3. Ibid.

4. Derek Law, "Do librarians have a future?" COFHE Bulletin 72 (Summer 1994), p.9.

5. Ibid.

6. Anne Goulding, "Student skills for the new European LIS market" in Proceedings of the 1st British-Nordic conference on library and information studies 22-24 May 1995, eds. Micheline Hancock-Beaulieu and Niels Ole Pors.
Copenhagen: Royal School of Librarianship, 1995, p.54.

7. Ibid.

8. Daniel Suvak, "The prison community," in Libraries inside: a practical guide for prison librarians; eds. Rhea Joyce Rubin and Daniel Suvak. (Jefferson: McFarland and Company, 1995), p.3.

9. American Library Association, Library standards for adult correctional institutions (Chicago: ALA, 1992), p.4.

10. Sandra Souza, "The professional staff," in Libraries inside; eds. Rhea Joyce Rubin and Daniel Suvak. (Jefferson: McFarland and Company, 1995), p.49.

11. S D Lithgow, "The development of performance indicators for prison libraries" in Proceedings of the 1st Northumbria international conference on performance measurement in libraries and information services 31 August - 4 September 1995, ed. Pat Wressell. (Newcastle Upon Tyne: Information North, 1995), p.101.

12. Sandra Souza, op.cit. p.50.

13. Andrew Green, "Local government reorganisation and its effect on library services," Community Librarian 15 (Summer 1994), 1.

14. Julie Blaisdale, "Local government reorganisation in Cleveland: effects on special needs provision," Community Librarian (Spring 1995), 4.

15. Alison Jago, "Approaching 2000: new challenges for the information professional" in New roles, new skills, new people. (Hatfield: University of Hertfordshire Press, 1995), p.50.

16. Jo Haythornthwaite, "Skills for today and tomorrow" in New roles, new skills, new people. (Hatfield: University of Hertfordshire Press, 1995), p.42.

17. Anne M. Galler, "Sensitizing the library community to the needs of disadvantaged persons," IFLA Newsletter; Section for libraries serving disadvantaged persons 39 (Fall 1994), p.10.

18. Ibid.

Dr Sue D. Lithgow, is a Department for Education and Employment Research Fellow, Department of Information and Library Studies, University of Wales, Aberystwyth. 